\title{
Filistorias
}

(PPGHIS/UnB) №. 30, Brasília, Jan - Jul 2017 ISSN 2316-1191

Recebido: 20/01/2017

Aprovado: 25/03/2017

\section{A representação como elemento de disputas identitárias: a Amazônia em disco}

Bibiana Soyaux de Almeida Rosa*

\begin{abstract}
Resumo: A cumbia é considerada, hoje, um gênero musical transnacional. Talvez um dos mais representativos de alguma latinidade - dada a capacidade deste gênero de se adaptar e se territorializar nas diferentes realidades do continente. Originária da Colômbia, desde a década de 1950, a cumbia se espalhou pelo continente latino-americano, ganhando relevância nos países em que se fixou. No Peru não foi diferente. Desde Lima até os limites da Amazônia peruana, a esse gênero musical foi absorvido, mesclado com outros ritmos e tornado, de alguma forma, elemento identitário daquelas regiões. O objetivo deste trabalho é analisar como a cumbia ganhou destaque e se consolidou como símbolo da música do oriente amazônico. Sendo assim, para esse artigo tomarei como objeto de pesquisa uma importante gravadora de discos da década de 1970, a Infopesa: relevante por apostar na cumbia selvática e levá-la das densas cidades amazônicas até a capital peruana como grande sucesso musical. Um dos principais grupos desse estilo musical é Juaneco y Su Combo, de Pucallpa. Neste trabalho, analisarei um disco lançado recentemente pela Infopesa, em que são recuperados os principais sucessos desse grupo, produzido pela gravadora durante as décadas de 1970 e
\end{abstract}

\footnotetext{
${ }^{*}$ Centro de Estudos e Pesquisas sobre as Américas (CEPPAC - ICS - UnB). Mestranda. Este artigo foi apresentado em comunicação oral na X ANPUH Regional seção Pará, em 2016.
} 
1980, a fim de perceber como o imaginário amazônico era representado a partir da música e pela produção musical.

Palavras-chaves: Cumbia Amazônica, Identidade Regional, Representação.

Abstract: Cumbia is considered nowadays a transnational musical genre. Perhaps one of the most representative of some latinity - given the ability of this genre to adapt and become territorialized in the most different realities of the continent. Originally from Colombia, since the 1950s it has spread to the Latin American continent, gaining relevance in the countries in which it has settled. In Peru it was no different. From Lima to the limits of the peruvian amazon, cumbia was absorbed and became, in some way, an identity of those regions. The objective of this article is to analyze how this musical genre gained prominence and became a symbol of eastern amazonian music. For this article I will take as object of research an important disc recorder of the 1970s and 1980s, Infopesa. They were relevant for investing on the Selvática Cumbia and taking it from the dense amazonian cities to the peruvian capital as a great musical success. One of the main groups of this musical style was Juaneco and Su Combo, from Pucallpa. In this work, I will analyze a disc recently released by Infopesa, that recovered the main successes of this group produced by the disc recorder during the decades of 1970s and 1980s, in order to perceive how the Amazonian imaginary was represented.

Keywords: Amazonian Cumbia, Regional Identity, Representation.

Quando se pensa em identidades culturais ou sociais se abre, automaticamente, um leque de possíveis aportes teóricos, abordagens e objetos de estudos frente à pesquisadora. É certo que posteriormente ao 'giro linguístico' das Ciências Sociais na década 1970, muitas correntes teóricas se debruçaram sobre tais temas e propuseram questões pertinentes para se pensar Foucault e Stuart Hall são dois grandes exemplos proeminentes quando falamos de mecanismos de formação de identidades culturais, sociais ou políticas. Uma das grandes contribuições que

\section{Alistorias}

(PPGHIS/UnB) No. 30, Brasília, Jan - Jul 2017 ISSN 2316-1191 
esse debate gerou para a compreensão dos processos identitários foi a de relacionar práticas discursivas às identidades; ou seja, as identidades sociais e/ou culturais não são tributárias diretas e necessariamente correspondentes ao real, mas sim produto e agente discursivos que se relacionam com suas bases materiais. É, portanto, interessante observar nas análises de formações identitárias os produtos simbólicos e os contextos nos quais tais processos se dão.

Nesse sentido, a música foi retomada nos estudos de identidades culturais como um elemento importante de representação social e de produção de sentidos. Entende-se que a música, além de ser uma linguagem mais acessível e versátil (do que a literatura ou o cinema, por exemplo), também tem a capacidade de denotar uma série de indicativos sociais, tais como os perfis de consumo, os gêneros musicais e sua regionalidade, etc. Por isso, a partir da década de 1970, muitas críticas a estudos já consagrados sobre música e sociedade se consolidaram e deram espaço para novas explicações para esta relação (música e identidades). Se retomarmos os estudos mais clássicos sobre este tema, vê-se uma tendência a relacionar os estilos musicais diretamente às classes sociais supostamente correspondentes a eles - em uma análise que se encerrava apenas no consumo. Esse tipo de abordagem das representações de tendência mais reflexiva sugere uma espécie de relação homóloga entre o indivíduo que escuta a música e a sua posição no tecido social.

É evidente que tais relações existem, e são passíveis observação; mas engessar a relação entre música e representação social dessa forma implica ignorar uma gama enorme de processos existentes ao gravar uma música, ao compor, ao escutar, ao comprá-la, ao escolher uma música como elemento constitutivo de sua identidade - e, claro, implica ignorar a subjetividade dos gostos de quem escuta a música e de quem a cria. A música é, portanto, um elemento multifacetado e plural, e para tomá-la como janela para análises sociais, é preciso compreendê-la para além de si mesma. É nesse sentido que as indústrias culturais adquirem um papel importante nos estudos em que a música é elemento de análise, uma vez que são chave para a compreensão dos modos de produção que envolve o mercado e a produção musical.

É importante retomar, neste momento, a trajetória que as indústrias culturais apresentam dentro das ciências sociais. Os filósofos da Escola de Frankfurt, como Walter Benjamim, abordaram este tema nas décadas de quarenta e cinquenta do século XIX. Traziam, em sua maioria, uma visão negativa no que diz respeito aos significados e consequências do crescimento

\section{Fitstorias}

(PPGHIS/UnB) No. 30, Brasília, Jan - Jul 2017 ISSN 2316-1191 
das indústrias culturais. Theodor W. Adorno escreveu especificamente sobre música, elaborando ideias como a 'remissão do ouvido' e 'música ligeira'1980,. Sua visão geral é de que a música produzida a partir da indústria musical (a música popular) era precária nos quesitos técnicos que lhe trariam caráter artístico. Ou seja, como muito bem coloca Raúl Renato Romero (2015: 8), a música popular, na opinião de Adorno, foi um fenômeno que transformou a música em mercadoria e, por conta disso, já não poderia ser considerada arte.

Muitas críticas já foram feitas às abordagens da Escola de Frankfurt no que diz respeito às indústrias culturais e às artes populares - dentre elas, a aproximação elitista e purista para se definir arte. E, além disso, estudos acerca das indústrias culturais se desenvolveram, a partir de outros locais geográficos, com abordagens mais interdisciplinares e, principalmente, em relação com os efeitos da globalização na cultura. Nesse sentido, considerando que as indústrias culturais necessariamente agregam valores econômicos e práticas mercadológicas em sua atuação, considerar seus produtos (música, cinema, novelas, etc.) como mercadorias ganha uma nova roupagem, a meu ver, diferente da proposta de Adorno. Primeiramente porque a distinção de arte 'erudita' e arte 'popular' já não é mais tão relevante - a indústria cultural está presente nos museus de arte clássica como também está presente na produção de show de músicas regionais/populares.

Em segundo lugar, devemos levar em conta as dimensões que o advento da globalização e do desenvolvimento tecnológico das comunicações nos traz para repensar a forma de se apreciar e/ou consumir arte. Volto agora para a temática central deste artigo, que é a música popular latino-americana, em especial a cumbia, e suas relações com a indústria cultural. Nos círculos acadêmicos, a musicologia se consolida, na Alemanha em meados do século XIX, como o estudo da música acadêmica europeia, e desta forma se difunde no restante do continente e nos Estados Unidos. Segundo Raúl Renato Romero (2015:7), apenas na década de 1950 que se pode verificar a etnomusicologia como outra forma de se abordar música nos países ocidentais. E ainda assim, a distinção entre música tradicional (popular) e a música ocidental permanece como marcador para o tipo de abordagem. No entanto, Romero defende que essa nova abordagem abriu caminho para a formação de um campo interdisciplinar aplicado em pesquisar os fenômenos musicais. Tais mudanças são sintomáticas no que diz respeito aos movimentos da produção e consumo de música - sejam eles na Europa ou nos países latino-americanos. O século XX foi um período de efervescência musical por conta de vários aspectos: os processos de urbanização, a intensificação

\section{Fitstorias}


das trocas comerciais, culturais e de informação entre países e regiões e, claro, à indústria radiofônica.

É a partir desses contextos que a categoria de análise "música urbana" surge e tensiona a musicologia e a etnomusicologia. A verificação de fenômenos musicais que carregam em si uma interação tão intrínseca entre músicas tradicionais, influências externas e a atuação da indústria musical como mediadora das relações de produção e consumo, forçou a revisão e superação de diversos conceitos e abordagens para os estudos da música. Pensando nessa transformação dos estudos sobre identidade cultural a partir da música, o sociólogo argentino Pablo Vila (1996) se dedicou à realização de um panorama sobre as principais abordagens teóricas que pretenderam suprir essas insuficiências da literatura tradicional, e a partir disso tentou apresentar algumas alternativas. Como resultado, nos apresenta a articulação e a interpelação como categorias de análise da música como elemento identitário. Para entender essas noções, é preciso ressaltar o caráter polissêmico da música enquanto linguagem que comunica sentidos. Como foi dito anteriormente, as expressões musicais são capazes de orientar diversas formas de identificações que não se encerram nas suas sonoridades ou no conteúdo de suas letras, isto é, quando existem.

Tomarei como base a noção de interpelação e articulação apresentadas por Pablo Vila, e considerando que a música é uma prática discursiva capaz que produzir sentidos, analisarei como a Amazônia era contundentemente representada na cumbia amazônica da década de 1970 - tanto na estética dos discos, como nas letras das músicas - e de que forma isso colaborou para a veiculação de um discurso identitário regional. Uma vez que a cumbia amazônica foi absorvida pela indústria musical e amplamente distribuída, o enfoque da minha análise se dará no contexto das condições de produção, ou seja: na atuação da Infopesa (Indústria Fonografica Peruana) como agente de articulação entre o produto simbólico (a música) e o discurso identitário retirado dele. Ou seja, da cumbia amazônica, repleta de elementos capazes de articular identidades regionais referentes à região amazônica, surge um tipo de discurso identitário relacionado à indústria cultural peruana. Primeiramente, apresentarei um panorama geral da história da cumbia e sua territorialização no Peru, para então seguir com a análise de um disco lançado recentemente pela Infopesa, que recuperou os principais sucessos de uma das principais bandas de cumbia amazônica da década de 1970, Juaneco y Su Combo.

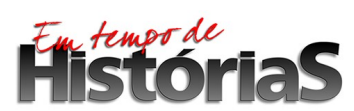

(PPGHIS/UnB) No. 30, Brasília, Jan - Jul 2017 ISSN 2316-1191 


\section{A Cumbia Amazônica}

A cumbia é um gênero musical originário da região costenha da Colômbia e compôs, juntamente com o vallenato e o porro, o que ficou conhecido como música tropical colombiana. Dentro do contexto do país, o que chamou atenção foi que o desenvolvimento desses gêneros musicais, a partir da década de 1940, tensionou a questão racial nos discursos identitários nacionais. A música tropical era anteriormente categorizada de forma simplista como folclórica por ser originária da costa caribenha, região periférica e de população majoritária negra. Não obstante, passou a ser o tipo de música mais vendido no país e a mais exportada também comunicando uma identidade colombiana que contrariava a narrativa identitária dominante do país (Wade, 2000: 2)

$\mathrm{Na}$ Colômbia, portanto, a cumbia comunicava uma identidade ligada à região costenha $\mathrm{e}$ caribenha do país, mas foi tomada como elemento identitário nacional e não parou por aí. A partir dos anos 1950, a cumbia extrapolou as fronteiras da Colômbia e caminhou pelo continente, territorializando-se e compondo diversas expressões musicais nas mais diferentes realidades latinoamericanas. A capilaridade da cumbia foi tão grande que hoje é considerada um objeto transnacional a ser pesquisado pelas Ciências Sociais, fértil para lançar luzes sobre as questões de identidades culturais na globalização. Segundo Pablo Vila e Héctor L'Hoeste (2013: 13), pode ser considerada o gênero musical mais difundido da América Latina. Ao pesquisá-la, é possível perceber mecanismos nos quais diferentes tipos de identidade (nacional, racial, regional, de gênero, etc) são ativadas, negociadas e incorporadas, de modo que sua expansão pelo continente pode revelar grande variedade de processos identitários impulsionados por ela ao se territorializar em diferentes países.

No Peru, a cumbia colombiana inicialmente teve maior impacto entre a juventude de classe média, mas rapidamente foi substituída pela salsa ou pelo rock britânico no consumo desses setores. A partir da década de 1970, ganhou espaço entre as populações urbanas de classe baixa, principalmente entre os migrantes andinos que tentavam se estabelecer em Lima (Wade, 2000: 174). Segundo Raúl Renato Romero (2007: 21-22), o advento da cumbia na música popular peruana é característica de dois processos: sua fácil aceitação em zonas rurais do país e sua hibridação com o huayno, música típica das populações Andinas do Peru. Para ele, tanto a 
popularização do huayno quanto a da cumbia se devem aos movimentos migratórios internos ao país.

Em momento anterior, o huayno rural se convertera em êxito comercial urbano - devido ao grande fluxo migratório das populações andinas à Lima, gerando um mercado interno urbano que consumia o huayno como forma de conexão com a experiência andina deixada para trás. A época de ouro do huayno comercial foi entre 1950 e 1980, período em que passou de um contexto local para um contexto nacional e que inaugurou no Peru a prática de uso de amplificadores, representações cênicas e outros recursos modernos para transcender seu regionalismo (Romero, 2007: 16). O huayno foi a música preferida dos imigrantes de Lima desta época e representava um mercado musical que também demandava outros gêneros musicais (por exemplo a salsa e o bolero), representando a experiência multicultural vivenciada por essas pessoas em uma grande cidade. Esse foi o cenário favorável que absorveu a cumbia colombiana a partir da década de 1960 e que, ao misturá-la com huayno ao longo dos anos 1970 e 1980, gerou o que foi considerado a cumbia peruana por excelência: a chicha.

Mas a influência da cumbia colombiana no Peru não se encerrou em Lima e não se limitou a representar a identidade do migrante andino nas regiões urbanas da capital. Apesar de não ter obtido tanta popularidade e circulação durante os anos 1970 e 1980, a cumbia amazônica foi um elemento importante para a formação da identidade regional na Amazônia (Metz. 2013: 171). Na região, o ritmo marcado da cumbia colombiana e o compasso acentuado pelos tambores de origem africana foram muito bem recebidos pelos mais variados ritmos populares da região inclusive a toada brasileira. Já na década de 1970 havia grupos musicais das regiões amazônicas que se identificavam como grupos de cumbia amazônica e faziam questão de evidenciar a identificação de suas músicas com a selva, como é o caso do grupo Juaneco y Su Combo, de Pucallpa, aqui analisado.

Outros grupos de cumbia selvática também surgiram nesta época, um exemplo emblemático é Los Mirlos e Garotos de Iquitos, que junto a Juaneco formaram o que se chamava de musica tropical de la selva. Foi do grupo Los Mirlos que surgiu a expressão poder verde, que se referia à floresta e à força da sua sonoridade, representada pelas músicas da região, em especial a cumbia. Assim, diferente da cumbia/chicha que tomou lugar de imediato em Lima e representava a vida do migrante andino - com músicas que poderiam causar sentimento de

\section{Filstorias}


nostalgia e letras carregadas de críticas sociais e de ilustração da vida em uma grande cidade -, a cumbia amazônica é predominantemente instrumental - com ênfase na guitarra - e é ornamentada com elementos sonoros que simulam sons da selva amazônica. As letras geralmente são simples e repetitivas, e fazem referência direta a elementos da região. Nelas estão presentes algumas características e elementos culturais específicos da Amazônia, tais como frutas, comidas, festas ou costumes.

\section{Ouvir, Sentir, Ser Música: Articulação e Interpelação}

É possível dizer que a cumbia é um gênero musical capaz de suscitar identificação e articulação a discursos identitários para a região amazônica. A cumbia selvática ilustrava a Amazônia, ou ao menos parecia transmitir a vivência da região a partir da sonoridade, evocando seus elementos ao compô-la - daí a expressão poder verde de la cumbia. Segundo Pablo Vila, a tendência de analisar a música a partir de uma pretensa homologia estrutural com o social começou a ser superada a partir das colocações de Althusser e Lacan, que partem da revisão da noção de ideologia de Gramsci somado a algumas colocações do pós-estruturalismo para esboçar a noção de articulação como orientadora dos processos identitários musicais. Em resumo, a teoria da articulação mantém a ideia de que há autonomia dos elementos culturais e ideológicos presentes nas manifestações musicais - porém é relativa. No entanto, tais elementos dialogam e negociam sentido com padrões econômicos, políticos, sociais e culturais que permeiam o contexto no qual a música acontece. Assim, a música é capaz de articular a produção de sentido a partir da relação entre seus elementos próprios e o contexto ao qual ela é produzida e consumida. Essa análise pode ser aplicada na relação entre as músicas, e suas criações musicais, com a produção e atuação das indústrias culturais, por exemplo.

Dentro da vertente mais pós-estruturalista, representada principalmente por Ernesto Laclau e Chantal Mouffe, foi formulada também a noção de interpelação como elemento de construção identitária. Nesta abordagem, a música popular ganha destaque por seu amplo alcance e reconhecimento de um número maior de pessoas. A teoria da interpelação sustenta que a música - principalmente as de expressão popular - é uma prática cultural capaz de fornecer às pessoas diversos elementos propícios para constituir múltiplas identidades. A música seria, nesse

\section{Fitstorias}

(PPGHIS/UnB) No. 30, Brasília, Jan - Jul 2017 ISSN 2316-1191 
sentido, poderosa no seu caráter interpelador por suscitar emoções e possuir um sentido cognitivo muito forte. Nesse sentido, a sonoridade - mesmo sem nenhum tipo de letra - pode ser um elemento definidor de processos de identificação. Segundo Pablo Vila, o poder de interpelação da música se intensifica por ser uma linguagem polissêmica:

Los múltiples códigos que operan en un evento musical (algunos de ellos no estríctamente musicales: códigos teatrales, de danza, linguísticos, etc.) explicarían la importancia y complejidad de la música como interpeladora de identidades, y esto es algo que la distinguiría de otras manifestaciones de cultura popular de carácter menos polisémico. A su vez, como el sonido en sí mismo es un sistema de estratos múltiples, los códigos estríctamente musicales también son variados (Apud Middleton 1990: 173). De ahí la posibilidad que tiene un mismo tipo de música de interpelar a actores sociales muy distintos, sobre todo si tenemos en cuenta que dichos códigos, lejos de reforzarse el uno al otro, muchas veces pueden ser altamente contradictorios. (Vila, 1996)

Para a realização deste artigo, os elementos a serem analisados serão as letras das músicas e a estética dos discos, o que perpassa, necessariamente, ao modo de produção desse gênero musical e sua absorção pela indústria musical ainda incipiente no Peru do final dos anos 1960 e durante a década de 1970. Assim, para a análise de caso, é essencial a compreensão do papel da indústria musical como agente de construção e comunicação desse discurso identitário regional a partir da cumbia amazônica.

\section{A Representação Como Ponto de Partida: A Amazônia Em Discos.}

A Indústria Cultural, inserida nas lógicas da globalização e do capitalismo, pode funcionar como agente articulador e interpelador de encontros interculturais e, assim, atuar na produção de discursos identitários de caráter regional - que mesmo localizados representam tendências transnacionais. Para este artigo, cabe estabelecer que encaro a temática das indústrias culturais latino-americanas a partir de um questionamento norteador para a reflexão: em um contexto de mundialização da cultura, de que modos elas rearticulam identidades regionais? No caso da cumbia amazônica, a indústria fonográfica participou de processos de hibridação cultural resultantes das fusões musicais na região amazônica bem como veiculou estilos musicais representantes desta região nos circuitos musicais peruano.

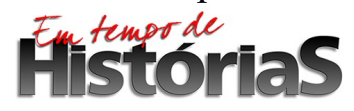

(PPGHIS/UnB) No. 30, Brasília, Jan - Jul 2017 ISSN 2316-1191 
Para a compreensão do processo da construção da cumbia amazônica como discurso identitário para a região, busco compreender a atuação de uma importante gravadora peruana, a Industria Fonografica Peruana (Infopesa). A Infopesa foi fundada no ano de 1971 pelo empresário Alberto Maraví, produtor musical peruano. Ele já atuava na cena musical desde a década de 1950: começou escrevendo comentários e resenhas sobre discos para periódicos e logo passou a trabalhar em rádios - momento que começou a comandar seus próprios programas, onde tocava os mais variados gêneros musicais do continente. A partir daí, deslanchou sua carreira como crítico e produtor musical: passou um bom tempo no Brasil, nas cidades Rio de Janeiro e São Paulo, onde trabalhou como produtor nas gravadoras Philips e comandou o programa 'Discómetro Mundial' na Rádio Tupi; passou um período em Nova Iorque pesquisando as influências caribenhas nos Estados Unidos, ganhando ainda mais visibilidade; e por fim, em 1966 foi convidado a liderar o setor internacional da famosa gravadora El Virrey, em Lima.

Passados 16 anos vivendo no exterior, Alberto Maraví finalmente retornou ao Peru. Pouco tempo depois saiu da gravadora que o havia levado de volta e se pôs a construir seu próprio negócio na música, investindo nas mais diversas expressões musicais do Peru, da costa norte até os limites da selva amazônica. Antes de fundar a Infopesa, abriu a Disco Independiente Nacional (Dinsa) em 1968, momento que entrou em contato com a cumbia ao viajar pelas cidades amazônicas peruanas pesquisando as festas populares e os ritmos que as embalavam. Assim, ao finalmente fundar a Infopesa, seu sucesso como produtor musical já era conhecido entre os grupos musicais peruanos, e já contava com importante capital social e financeiro para tocar seu negócio para frente. $\mathrm{O}$ que chama a atenção nesta trajetória é a intenção clara de apostar em grupos locais de todo o Peru e levá-los ao eixo principal da indústria musical nacional à época e ainda, a precisão em escolher os grupos certos para lançar. Por isso, a atuação da Infopesa nesse período da história da música peruana representa um exemplo interessante de como as indústrias musicais podem exercer papel importante na formação de discursos identitários regionais e nacionais a partir da música.

Ao longo dos anos 1970, a gravadora apostou nos grupos de cumbia amazônica - e não somente, uma vez que era um selo musical especializado em músicas populares peruanas. Já no início de seu funcionamento foi responsável por produzir importantes nomes da região, como Los Mirlos e Juaneco y Su Combo, já citados anteriormente. A produção artística da música e a 
maneira pela qual foi trabalhada e distribuída pela gravadora atuam juntas na produção do discurso identitário proeminente da cumbia amazônica. O CD escolhido para a realização do artigo é um lançamento recente da Infopesa, que em 2012 retomou os trabalhos após o fechamento da empresa no final da década de 1980. A empresa voltou a atuar, primeiramente, com a intenção de recuperar o material que fora guardado desde seu funcionamento, remasterizar os áudios e relançar os sucessos da época, garantindo um público mais velho. Para alcançar o público mais jovem, apostou em discos bem estilizados, valorizando as artes das capas e disponibilizando o material na internet, pelo Youtube e Spotify.

Juaneco y Su Combo foi e ainda é uma banda muito popular no Peru, conhecida por ser determinante para a olla amazónica da cumbia peruana. Foi formada no começo da década de 1960, liderada por Juan Wong Paredes, natural da cidade amazônica de Pucallpa. A princípio, o objetivo do grupo era tocar músicas de repertório nas festas populares e em eventos públicos em Pucallpa e em outras cidades próximas, como Iquitos, Moyabamba e Tarapoto. Seu filho, Juan Wong Pong Popolizio, se juntou ao projeto após cumprir serviço militar e retornar a casa. O próximo passo foi contratar um exímio músico da região, Noe Fachín, para entrar no grupo como primeiro guitarrista. Fachin foi um integrante chave para o grupo. Foi um grande compositor e se tornou uma lenda como guitarrista - sendo até hoje recordado como "el brujo Fachin", em uma referência aos shamãs da cultura shipibo, muito respeitados na região.

O grupo se completou com a contratação de mais seis integrantes, naturais da cidade. Todos eles eram jovens pertencentes à Tribo Chama, localizada próxima à orla da Laguna de Yarinacocha - cartão postal de Pucallpa e plano de fundo de vários LP's de Juaneco y Su Combo. Compartilhavam do apreço e admiração pela música tropical e os ritmos tradicionais, mas também tinham acesso às frequências de rádio de cidades próximas, recebendo influências também do Brasil e da Colômbia. Antes da oficialização do grupo em 1968, Juan Wong Paredes se retirou e nomeou seu filho como diretor da banda. Sendo assim, a primeira formação oficial foi a seguinte: Juan Wong Ponpolizio como diretor e tecladista; Wilindoro Cacique como vocalista, tocando também o reco-reco e o pandeiro; Noe Fachín com a primeira guitarra e principal compositor; Walter Domínguez Oñate com o baixo eletrônico; Rosendo Hidalgo com os timbales; Wigberto Muierta Bardales como o segundo guitarrista; Juvenico Pinchi Sangama com as congas e Jairo Aguilar Tejada como bongô.

\section{Filstorias}

(PPGHIS/UnB) №. 30, Brasília, Jan - Jul 2017 ISSN 2316-1191 
Eram muito populares na região, e eventualmente iam a Lima - principalmente para comprar instrumentos novos. Foram contratados pela Infopesa em 1972. No encarte do disco a ser analisado, o próprio Alberto Maraví escreve as memórias de como ouviu falar de Juaneco y Su Combo, de seu primeiro contato como grupo, e como se deu a relação entre a banda e a gravadora:

Esta formação de Juaneco y Su Combo iniciou ensaios para um novo repetório dançante, o qual compreendia uma fusão dos ritmos estrangeiros com as cumbias instrumentais do típico sabor tropical amazônico. Este repertório contava com músicas como 'Me robaron mi runa mula', escrita por el 'Brujo' Noe Fachin e a cumbia 'Ya se ha muerto mi abuelo' com melodia e letra de Juan Wong, Wilindoro Cacique e Walter Dominguez. Seus sucessos musicais mencionavam costumes $\mathrm{e}$ as cidades dos músicos, seus ancestrais e, principalmente, recordavam as férias e festas tradicionais das cidades e povos amazônicos. Nesta região, Juaneco y Su Combo se apresentavam com a típica e vistosa indumentária shipiba, o que era apreciado e bem recebido por seus fãs. Em 1972, conheci e pude escutar Juaneco ao vivo em uma calorosa tarde de sábado em Iquitos, e os convidei para viajar até Lima. Nesse momento, gravamos o primeiro disco nos estúdios da Infopesa, local em que se iniciou e perenizou o "Poder Verde" da cumbia amazônica. (Maraví, 2015, tradução livre da autora)

Nesse mesmo ano, 1972, Juaneco y Su Combo gravaram nos estúdios da Infopesa suas primeiras músicas, lançadas em 45 RPM - formato de vinil que comportava duas músicas, utilizado para divulgar os singles recentes dos artistas. As músicas deste primeiro lançamento foram "A la fiesta de San Juan" (Imagem 1) e "Me robaron mi runa mula" (Imagem 2). Estes singles serviram de divulgação para o primeiro LP completo - de 33 RPM - da banda, gravado no mesmo ano pela Infopesa - "El Gran Cacique". Este LP foi uma estreia de absoluto sucesso (Imagem 3). Contava também com músicas que hoje são consideradas clássicas da cumbia peruana: a versão em espanhol da nossa "Mulher Rendeira", e "Vacilando con Ayahuasca", uma composição belíssima de Noe Fachín.

\section{Fitstorias}




\section{Imagem 1}

(retirada do site Discogs: https://www.discogs.com)

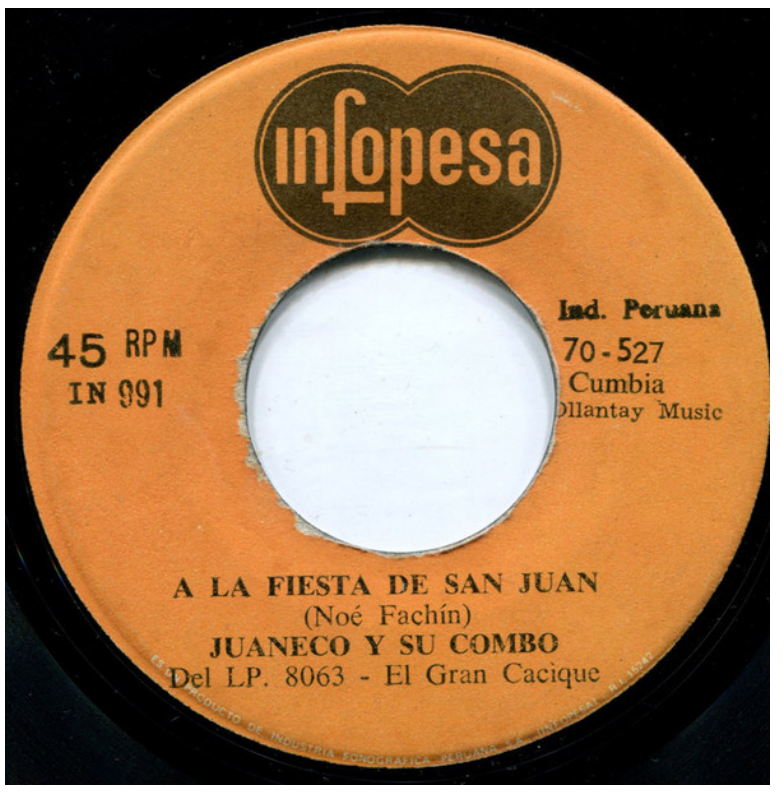

Imagem 2

(retirada do site Discogs: https://www.discogs.com)

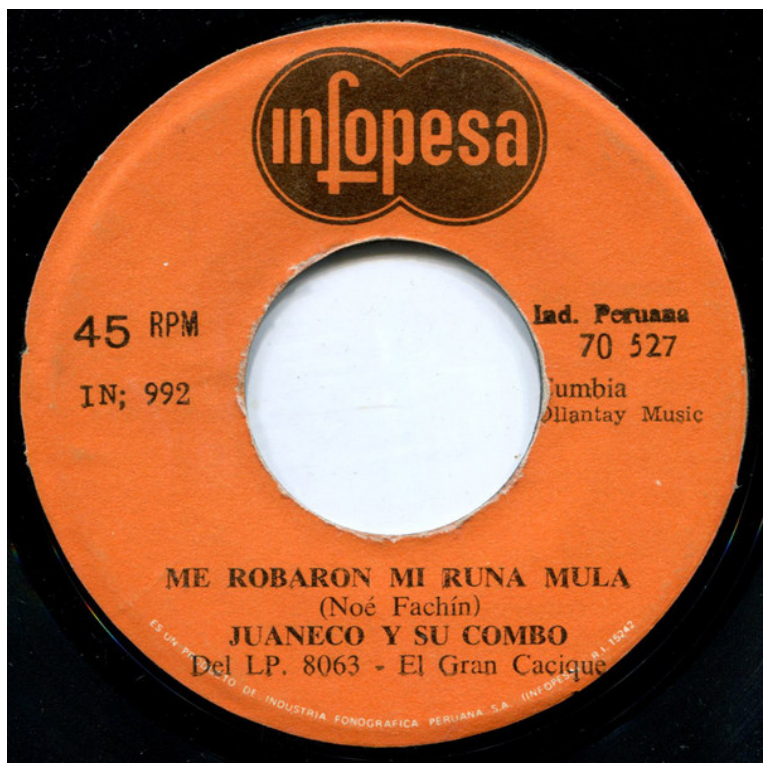

\section{Alistorias}

(PPGHIS/UnB) №. 30, Brasília, Jan - Jul 2017 ISSN 2316-1191 


\section{Imagem 3}

(retirada do site Discogs: https://www.discogs.com)

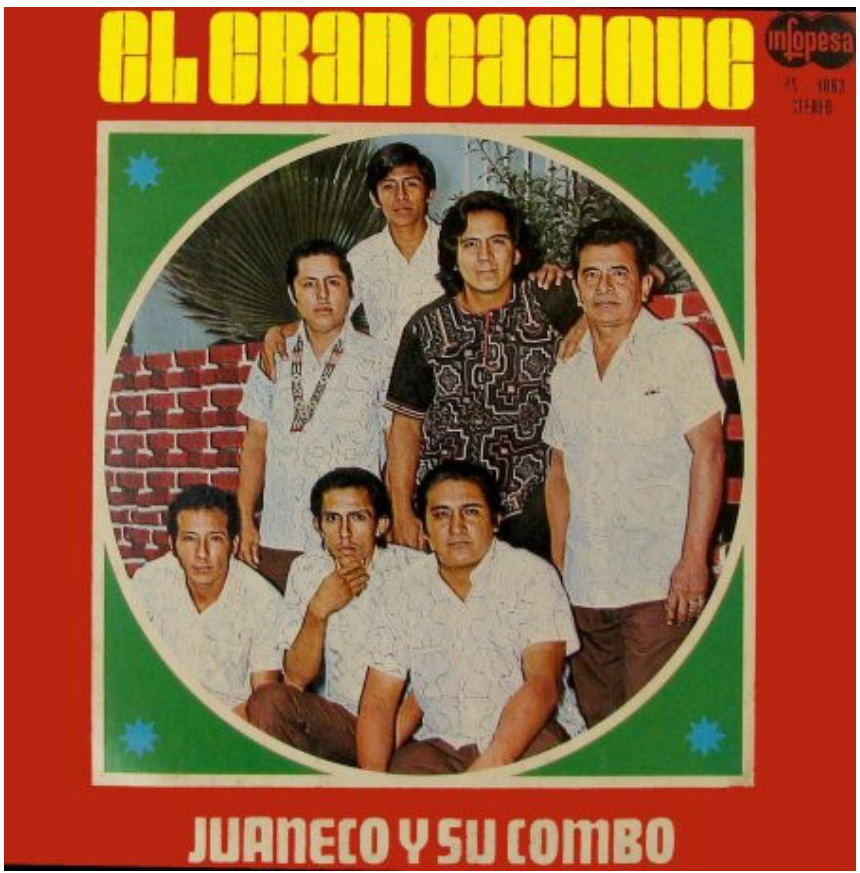

Ao todo, o LP continha seis músicas no lado A e mais seis no lado $\mathrm{B}$, formato padrão dos LP's em 33 RPM:

Lado A

1. Me robaron mi Runa Mula (Noe Fachín) 00:00

2. Agüita de Sachachorro (Noe Fachín) 03:14

3. La marcha del sapo (Noe Fachín) 05:55

4. La sirenita enamorada (Juan Wong P.) 08:36

5. El pajarito pajero (Noe Fachín) 11:31

6. El capullito (Noe Fachín) 14:30

\section{Lado B}

1. Vacilando con ayahuasca (Noe Fachín) 17:23

2. Mujer hilandera (D.R.) 20:58

3. Cumbia pa' la sierra (Wálter Domínguez) 24:53

4. Volando (Noe Fachín) 27:51

5. Bolero para ti (Wálter Domínguez) 30:56

6. La incognita (Juan Wong P.) 34:23

Produção: Alberto Maraví

\section{Fistontorias}

(PPGHIS/UnB) No. 30, Brasília, Jan - Jul 2017 ISSN 2316-1191 
Editorial: Ollantay Music.

A maioria destas músicas são cumbias instrumentais, apresentando influências fortes do carimbó e toadas do Brasil, uma vez que Pucallpa é próxima da fronteira amazônica brasileira. Sua sonoridade é diferente de outros grupos de cumbia amazônica, como Los Mirlos, que eram de Moyobamba, cidade da amazônia altiplana e, portanto, com mais influências de ritmos do altiplano e serra peruana. Neste LP, quando há letra nas músicas, são apenas intervenções rápidas, com expressões como "Dale Juaneco", na introdução de "Robaron mi runa mula", "Dame más ayahuasca" em "Vacilando con ayahuasca", "Vamos a la playa" em "A la fiesta de San Juan". Desse LP foram selecionadas quatro músicas para compor o CD aqui analisado, recém-lançado pela Infopesa (Mi robaron mi runa mula; Vacilando com Ayahuasca; Mujer Hilandera e Volando). Além destas, o single “A la fiesta de San Juan” também foi incluído.

O disco "Juaneco y Su Combo - leyenda amazónica", de 2016, faz parte da produção musical que a Infopesa tem se empenhado desde a retomada de seu funcionamento. Hoje em dia, além da direção de Alberto Maraví, a empresa conta com seu filho, Juan Ricardo Maraví, como produtor executivo. Pude entrevistar os dois e perguntá-los sobre o significado da reabertura da Infopesa, com o que me responderam que o intuito é rememorar com os mais velhos a origem da música tropical peruana e oferecer aos mais jovens a experiência de testemunhar uma identidade em formação. Por isso, apostaram no poder da memória de suscitar algum sentimento de pertença a partir dessa sonoridade retomada, conquistando um público mais velho - já que até então se não dos LPs ou cassetes originais, só se podia ouvi-la em gravações de baixa qualidade no YouTube. Por outro lado, ao repensar as estéticas dos discos e as formas de marketing da gravadora, eles apostaram no público jovem, latino-americano, que busca suas origens e é curioso a respeito das diferentes manifestações culturais do país ou da região. A capa deste disco é representativa dessa estratégia: 


\section{Imagem 4}

(acervo pessoal)

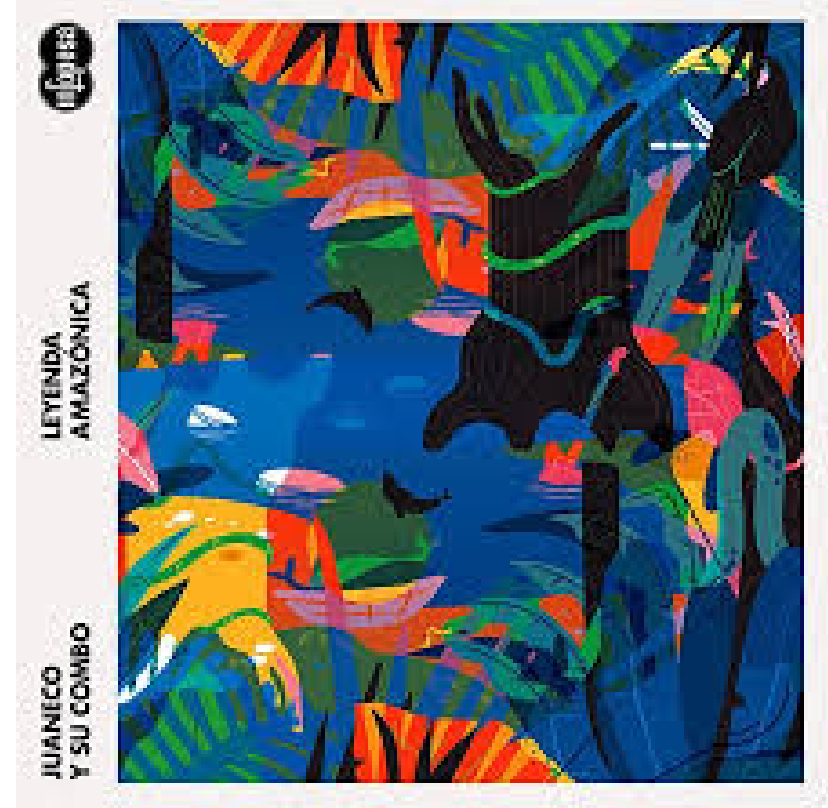

A arte utilizada, de aspecto moderno, traz elementos da selva amazônica que são utilizadas na música de Juaneco y Su Combo, como as "tahuampas", as folhagens da região, árvores, tudo isso em uma fusão de cores que suscitam a psicodelia que é característica da sonoridade da cumbia amazônica - graça à inserção da guitarra e dos sintetizadores na composição. Na contracapa do disco, há uma foto retirada dos arquivos da Infopesa, que fora utilizada como material de divulgação da banda. Nela, os integrantes da banda estão com as vestimentos do povo shipibo em uma embarcação típica para navegar curtos trechos do rio Ucayalli. Grande parte das imagens de divulgação do grupo contam com essa estética e, sempre que tocavam em regiões da Amazônia peruana, usavam essas vestimentas nos shows. Quando não era o grupo inteiro, pelo menos o vocalista se apresentava dessa maneira. Por isso ficou conhecido como Wilindoro Cacique, e também por agregar às suas vestes caciques da cultura shipibo.

Outra coisa interessante a ser observada é a escolha gráfica e tipográfica que compõem as capa dos vinis, juntamente com a evocação da paisagem amazônica. A escolha estética geralmente observada nos discos de vinis é de abusar do colorido, usar cores fortes e vibrantes.

\section{Hitistorias}


Além disso, somado ao nome do grupo em destaque, há dizeres convidativos quanto à música da Amazônia, ou da selva em si. Expressões comuns nas capas dos discos como "Vamos a la selva"; "Ven a bailar con Juaneco"; "La musica del oriente para o mundo" denotam que além de ter o intuito de representar a região amazônica, a música e dos discos são porta de entrada para que a região se faça conhecida para além de suas cidades.

A estética dos discos e seu tom entusiasta e convidativo sobre a floresta Amazônica converge com a sonoridade das músicas e suas letras. Ao contrário da cumbia colombiana da década de 1940-50, e a chicha limense da década de 1970, a cumbia amazônica é mais instrumental e acrescentou mais elementos sonoros à composição, misturando ritmos típicos da região como a toada brasileira e a chimaycha e a pandilla, do Peru. O ritmo da cumbia amazônica, portanto, é festivo e dançante. Quando há inserção de letras, a estrutura é a seguinte: uma estrofe inicial que introduz os elementos a serem exaltados pela música, e um refrão que se repete durante toda a música. As músicas que se enquadram nesse sentido são: Ya se ha muerto mi abuelo (faixa 1); Vacilando con Ayahuasca (faixa 7); Dale Juaneco (faixa 12); Me robaron mi runa mula (faixa 15). Os títulos das músicas, como se pode observar na capa traseira do CD (Imagem 5) são bem ilustrativos dessa tendência.

\section{Imagem 5}

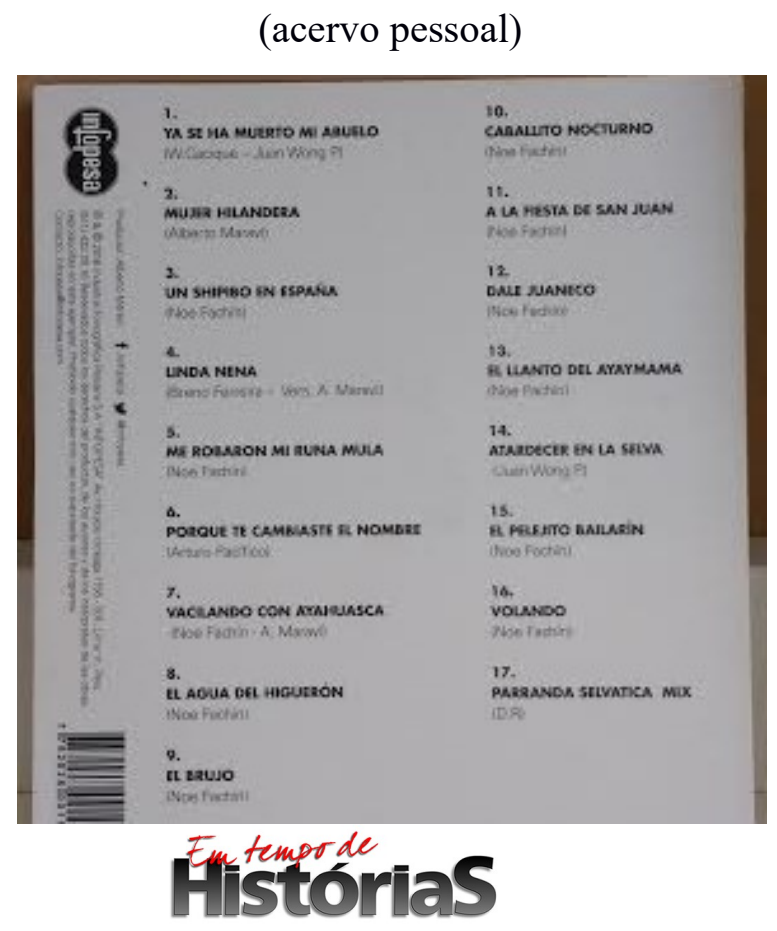


Observa-se também que em nenhum momento a região amazônica é diretamente vinculada ao Peru nas cumbias amazônicas, salvo algumas exceções. O discurso que se constrói a partir da música e dos discos é de caráter regional, apesar de ser possível perceber algumas intenções de reivindicar a importância da cultura selvática para o imaginário nacional. Em algumas faixas essa conexão com o regional são mais explícitas, já pelo título da música, como "Un Shipibo em España" - lembrando que shipibo é o nome do grupo étnico predominante em Pucallpa; "Parranda Selvática" - parranda é o nome de uma dança festiva, muito popular em várias regiões do Peru; "Vacilando com Ayahuasca" - vacilando, no oriente peruano, tem a denotação de se divertir, gozar de algo e, claro, aparece um elemento famoso das regiões amazônicas do continente e das culturas indígenas, os rituais de ayahuasca.

Elencarei três músicas que sugerem o elemento regional com mais ênfase, não só por suas letras, mas por seus contextos de produção. Como foi dito anteriormente, Juaneco y Su Combo começou com intenção de tocar em festas tradicionais, e de fato assim era a vivência musical de grande parte dos músicos da região. A festa de 'San Juan' é tradicional e importante no calendário peruano, no entanto a região amazônica é destaque no Peru pelas maneiras que as cidades celebram o 24 de junho. Em Ucayali, distrito onde se encontra Pucallpa, se comemora San Juan com feiras à beira rio, e à noite as pessoas entram nos rios, em um ritual de purificação. $O$ jornal peruano La República, em cobertura acerca das festividades juninas, define as festas de San Juan da seguinte maneira:

Todo 24 de junho se celebra a Festa de São João. Entretanto, as grandes celebrações começam um dia antes. À noite, as pessoas se dirigem até os grandes e abundantes rios para purificar-se, pois para eles, nesse dia todas as águas da selva peruana possuem virtudes criativas e creem que ao se banharem nestas águas abençoadas por São João Batista, gozarão de uma vida feliz e saudável pelo restante do ano.

Pensar na Festa de São João é pensar na selva peruana, são nas cidades de Pucallpa (Ucayali), Tingo Maria (Huánuco), Iquitos (Loreto), Tarapoto e Moyobamba (San Martín), que os turistas nacionais e estrangeiros vão para desfrutar da festa da selva e admirar seus belos paraísos naturais. (La Republica, 24 de Junho de 2014 - tradução livre da autora)

“A La Fiesta de San Juan”, um dos primeiros singles de Juaneco y Su Combo, remetem a essa tradição. Predominantemente instrumental, a música começa com os seguintes dizeres do

\section{Aitstorias}

(PPGHIS/UnB) No. 30, Brasília, Jan - Jul 2017 ISSN 2316-1191 
vocalista: "Vamos a la playa! Vamos a banharnos! Hay que llamar las chicas! Cuidado con las raias, cuidado con las raias! Tropical Tropical! [...] Vamos a la fiesta de San Juan! Dale Juaneco!". E então começa a música instrumental. Em comparação com outras músicas de Juaneco, esta, por ser específica de uma celebração tradicional da região, apresenta uma sonoridade maior com os ritmos típicos da tradição indígena dos shipibos. No entanto, ainda há a presença da guitarra e dos instrumentos de percussão típicos da cumbia colombiana.

Além da evidente referência a festas, tradições e de natureza amazônica na cumbia amazônica, Juaneco y Su Combo apresentam outro fator de identificação regional - que supera as fronteiras nacionais, ou as tensiona - a partir de sua produção musical. Dois de seus grandes sucessos são versões de música brasileiras. Em Linda Nena (faixa 4), a música se inicia com o vocalista convidando sua parceira a ir ao Brasil: "Ven mi linda Nena, que nos vamos al Brasil". Esta música se trata de uma canção denominada "Andorinha Preta", do grupo Trio Irakitan, do Rio Grande do Norte. Além disso, e talvez ainda mais emblemático quanto à interação cultural do continente a partir da Amazônia, é a interpretação em cumbia da música Mulher Rendeira, do Zé do Norte, pelo grupo na faixa 1 desse disco, Mujer Hilandera. Em entrevista a um portal brasileiro de música, Senhor F, Alberto Maraví conta sobre essa gravação:

\footnotetext{
Senhor F - Juaneco y Su Combo gravou Mulher Rendeira/Mujer Hilandera, música do nordeste brasileiro. Eles eram de Pucallpa, cidade-irmão de Cruzeiro do Sul, no Acre, Brasil, que recebeu muitos nordestinos, com o fim do ciclo da borracha e, nos anos sessenta, com o "boom" de petróleo na região. Achávamos que essa proximidade de fronteiras e culturas poderia explicar o registro, mas descobrimos que foi você quem apresentou a música a eles. Como foi isso? Porque você apostou nessa música?

Alberto Maravi - Quando trabalhava na Rádio Tupi de São Paulo, eu tinha um programa também chamado Discômetro Mundial e nele entrevistei Zé do Norte, quem me apresentou a canção Mulher Rendeira, que por sua vez foi incluído no filme "O cangaceiro", homenageado no Festival de Cannes. Eu o entrevistei e rapidamente pude situar a música e considerei ideal para lançá-la no Peru com algum grupo amazônico, adaptando-a pessoalmente ao espanhol. Cabe ressaltar que esta canção já era um tema tradicional de domínio público da região nordeste do Brasil. (Portal Senhor F, 03 de Julho de 2013)
}

Este episódio é interessante para perceber como também é importante a visão e atuação de produtores musicais na criação de sucessos e de assessoramento de grupos musicais. Percebe-se,

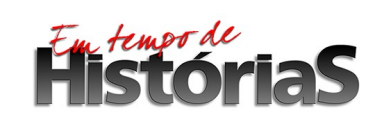

(PPGHIS/UnB) No. 30, Brasília, Jan - Jul 2017 ISSN 2316-1191 
portanto, que a produção de um discurso identitário da região amazônica a partir da música não foi construída apenas a partir da expressão musical em si. Ela, como linguagem, foi absorvida pela indústria musical e transformada em um sistema de representação eficaz para comunicar tal discurso, que contou com diversos símbolos: a sonoridade da música, suas letras, e a estética dos discos. Outros fatores poderiam ter sido levantados aqui, como a importância da rádio para a difusão desses grupos e fomentação do estilo musical.

A partir do exposto, creio ser possível estabelecer que o gênero musical cumbia, no Peru, possui ampla abrangência e representa um estilo popular dentro da tradição musical no país. A cumbia amazônica é um estilo cuja composição é contundamente representativa de sua região. E essa representação primeiramente se estrutura a partir da criação artística da música. Em outras palavras, depende da vivência dos musicistas, é resultado de fusões musicais ocorridas dentro de suas fronteiras, sugere quais tipos de ritmos e gêneros musicais são consumidos naquela região ao ponto de surtir efeitos nas produções musicais da região e, por fim, demonstra pontos de integração com o restante do país, mas também além das fronteiras peruanas - como é o caso da influência do carimbó e da toada nas músicas de Juaneco.

Essa é uma face do poder da música em produzir discursos identitários - uma face que acredito poder afirmar que é espontânea e nos fornece os elementos capazes de promover o que Pablo Vila denominou 'interpelação'. Ou seja, a partir de seus códigos, da sua sonoridade, suscitam sentimentos de pertencimento e de identificação com a região: evidenciam laços que já estão lá, a música selaria tais laços - ou então os tornaria mais vivos. Juaneco y Su Combo, portanto, são agentes chaves por representarem esse vínculo a partir de sua música. Por outro lado, a efetividade deste discurso identitário também depende da circulação da música. É nesse sentido que as indústrias culturais - essenciais para a compreensão das formas musicais contemporâneas - entram na equação. Elas são centrais nos contextos de produção desse produto simbólico. Inclusive, são responsáveis por tornar a música em produtos simbólicos com potencial de se popularizarem. Por isso, atribuo à Infopesa aos processos de articulação de tal discurso identitário; uma vez que a partir dela a cumbia amazônica de Juaneco y Su Combo e de outros grupos fossem distribuídas de forma mais ampla, chegando a Lima e em outras regiões do Peru.

Ao comunicar essa mensagem tão rica em elementos da cultura selvática, a cumbia amazônica se fortaleceu ainda mais dentro de sua própria região - fortalecendo seu caráter 
identitário amazônico. Juaneco y Su Combo representou, na década de 1970 um ícone da música tropical do Oriente, levando o espírito da selva para o restante do Peru e, com o advento da internet e o retorno da Infopesa em 2012 em bases digitais, hoje reaparece com as possibilidades de alcance internacional. O uso de representação da selva, pelo grupo na composição das melodias e nas letras de suas músicas, juntamente com a atuação da Infopesa, inserindo um senso estético como forma de potencializar e comunicar essas representações, foram eficazes em produzir um discurso identitário pugente para a região Amazônica.

\section{Referências Bibliográficas}

\section{Discografia}

Mi robaron mi runa mula (Lado B); 45 RPM, Juaneco y su Combo. 1972: Infopesa, Editorial Olantay.

El Gran Cacique; Disco Vinil LP. 1972: Infopesa, Editorial Olantay.

Juaneco y Su Combo - leyenda amazónica; CD Room. 2016; Infopesa: Editorial Olantay

\section{Fontes Secundárias}

ADORNO, Theodor W., et al. O fetichismo na música e a regressão da audição. Os pensadores, 1999, 48: 173-199.

D’AMICO, Leonardo. “Cumbia Music in Colombia: Origins, Transformations and Evolution of a Coastal Music Genre” Em: L'Hoeste, Héctor Fernández, and Pablo Vila, eds.Cumbia!: Scenes of a Migrant Latin American Music Genre. Duke University Press, 2013.

IANNI, Octávio. As Ciências Sociais na época da globalização. Revista Brasileira de Ciências Sociais. Vol. 13 n. 37 , São Paulo, Junho de 1998.

L'HOESTE, Héctor. Vila, Pablo. “Introduction” Em: L'Hoeste, Héctor Fernández, and Pablo Vila, eds. Cumbia!: Scenes of a Migrant Latin American Music Genre. Duke University Press, 2013.

METZ, Kathryn. "Pandillar in the Jungle: Regionalism and Tecno-cumbia in Amazonian Peru" Em: L'Hoeste, Héctor Fernández, and Pablo Vila, eds. Cumbia!: Scenes of a Migrant Latin American Music Genre. Duke University Press, 2013.

\section{Hitistorias}

(PPGHIS/UnB) No. 30, Brasília, Jan - Jul 2017 ISSN 2316-1191 
MONETA, Carlos Juan. "Identidades y politicas culturales em procesos de globalización e integración regional" em: Canclini, García; Moneta, Carlos Juan (orgs). Las industrias culturales en la integración latinoamericana. Cidade do México: Editorial Grijalbo, 1999.

NAYO, Aragón. Infopesa: El despertar de um gigante de la música peruana. 15 de Dezembro de 2015. Disponível em: https://redaccion.lamula.pe/2015/12/15/infopesa-el-despertar-de-un-gigante-de-la-musica-peruana/nayoaragon/

ORTIZ, Renato. Mundialização e Cultura. São Paulo: Editora Brasiliense, 1994.

PÁEZ, Ángel. El Rey Midas de La cumbia. 11 de Dezembro de 2011. Disponível em: http://larepublica.pe/11-122011/el-rey-midas-de-la-cumbia

ROMERO, Raúl. “Andinos y Tropicales. La cumbia peruana em la ciudad global”. Lima: Pontificia Universidad Católica del Perú, Instituto de Etnomusicologia, 2007.

ROMERO, Raúl (Editor). "Musica Popular y sociedad en el Perú contemporâneo". Lima:Pontifica Universidad del Perú, Instituto de Etnomusicologia, 2015.

ROSA, Fernando. Alberto Maraví, coração americana. 03 de Julho de 2013. Disponível em: http://portal.senhorf.com.br/interna.php?P=306

S/A, La Fiesta de San Juan se celebra a lo grande en la Amazonía peruana (FOTOS). 24 de Junho de, 2014. Disponível em: http://larepublica.pe/23-06-2014/la-fiesta-de-san-juan-se-celebra-hoy-con-total-fervor-y-algarabia

VILA, Pablo. Identidades narrativas y musica. Una primera propuesta para entender sus relaciones. Em: Revista Transcultural de Música (2) A.288, 1996.

WADE, Peter. Music, Race and Nation. Chicago: The University of Chicago Press, 2000.

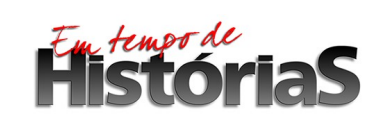

(PPGHIS/UnB) №. 30, Brasília, Jan - Jul 2017 ISSN 2316-1191 